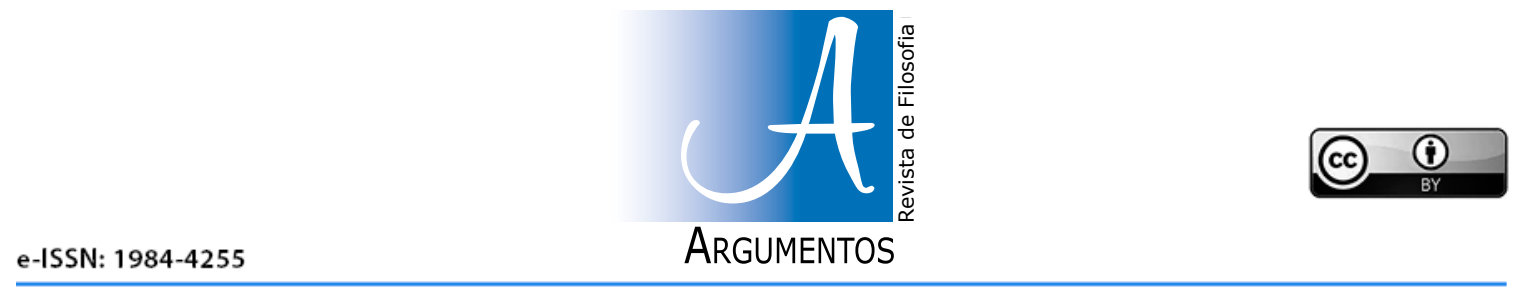

D0I: https://doi.org/10.36517/Argumentos.23.10

TRADUÇÃO

\title{
O caso Heidegger
}

\section{WEIL, Eric. Le cas Heidegger. Les Temps Modernes 2/22 (1947), p. 128-138}

\author{
Judikael Castelo Branco \\ (Tradução e apresentação) \\ https://orcid.org/0000-0002-4551-2531 -E-mail: judikael79@hotmail.com
}

\section{Apresentação}

\section{Eric Weil e $O$ caso Heidegger}

Retomar um texto como Le cas Heidegger mais de sete décadas depois de sua publicação demanda com certeza uma justificativa. Para atender a essa exigência, organizamos essa introdução em duas partes distintas: em primeiro lugar, destacamos alguns traços essenciais do cenário atual do "caso Heidegger"; depois, passamos propriamente à apresentação do artigo de Eric Weil.

Podemos dizer com muita tranquilidade que a discussão sobre a relação de Heidegger com o nazismo não só ressurge de tempos em tempos, mas que, na verdade, ela nunca é de todo esquecida. No entanto, a história dessa discussão conheceu recentemente três momentos de notável recrudescimento. Aludimos precisamente à repercussão do livro do chileno Víctor Farías, Heidegger et le nazisme, em 1987; e um segundo momento, em 2005, movido pela publicação de Heidegger: l'introdcution du nazisme dans la philosophie, de Emmanuel Faye. ${ }^{1}$ No entanto, os rumos hodiernos da discussão são ditados pela publicação dos Scwarzen Hefte ${ }^{2}$, os

\footnotetext{
1 Podemos adiantar que o livro de Faye (2005) sustenta uma leitura diametralmente oposta à interpretação de Weil, é o que se vê, por exemplo, quando já no início do texto afirma que "o estudo profundo dos seus escritos revelou-nos progressivamente que, longe de marcar unicamente a linguagem, a realidade do nazismo com que fomos confrontados lendo Heidegger inspirou na sua integralidade e alimentou até às suas raízes a sua obra, de tal modo que já não é possível dissociá-la do seu envolvimento político" (p. 18). Curiosamente a conclusão já está dada e o autor defenderá essa tese em todas as páginas do livro, chegando finalmente à conclusão de que se deve "pôr em questão a própria existência de uma filosofia de Heidegger" (p. 444).

2 Diana Stephan (2016, p. 235) apresenta os Cadernos negros nos seguintes termos: "Desde fevereiro de 2014 e sob a edição do diretor do Martin-Heidegger-Institut na Universidade de Wuppertal, Peter Trawny, foram publicados quatro dos nove tomos dos Cadernos negros no marco da publicação da Gesamtausgabe de Martin Heidegger. Esses tomos contêm mais de 1.700 páginas e correspondem ao grupo dos manuscritos chamados Überlegungen e o último deles publicado em 2015, com o título de $A n-$ merkungen. A partir de 1931, e até o início dos anos de 1970, Heidegger plasma seus pensamentos em pequenos cadernos encapados de preto - daí seu enigmático nome. Entretanto, o que é verdadeiramente enigmático nos Cadernos não está realmente
} 
Cadernos negros de Heidegger, a partir de 2014. ${ }^{3}$ Se, por um lado, no que concerne à questão do nazismo de Heidegger, é possível dizer que os Cadernos não acrescentam de fato grandes novidades ${ }^{4}$, por outro, como põe acertadamente Edgar Lyra (2015, p. 56), o problema agora é definir o quanto as "crenças ignóbeis" do autor de Ser e tempo contaminam a sua obra. A questão é complexa já no seu enunciado, pois que metro permitiria distinguir os limites dessa contaminação? Qualquer resposta à pergunta trará uma série incontornável de outras questões igualmente sérias. Se a "não contaminação" é quase indefensável, a tese de uma "contaminação total", como lembra Lyra, obrigaria a lidar com o assombro que a obra de Heidegger produziu em pensadores como Derrida, Gadamer, Löwith, Marcuse, Arendt, Foucault e Agamben, por exemplo. Em outros termos, como se deveria tratar do espectro do legado filosófico de Heidegger? A leitura dos Cadernos apenas começou, mas, de modo geral é possível afirmar duas coisas: primeiro, que a principal referência para quem deseja adentrar nessa seara é o livro de Peter Trawny, Heidegger und der Mythos der Jüdischen Weltverschwörung, de $2014^{5}$, e, segundo, que as declarações antissemitas de Heidegger têm sido o "epicentro hermenêutico dos Cadernos", ou seja, o lugar a partir do qual eles são interpretados. ${ }^{6}$

As discussões estão muito distantes de uma solução capaz de apaziguar os debatedores e a nossa descrição certamente não faz justiça ao seu contexto. No entanto, nosso objetivo é apenas levantar aspectos do cenário atual para retomá-los, ao final, à luz das reflexões que Weil propõe no artigo que agora apresentamos.

O texto de Eric Weil, Le cas Heidegger ${ }^{7}$, se encontra noutro momento da história dessa discussão, de forma precisa no período que segue imediatamente a Segunda Guerra. Originalmente publicado em $1947^{8}$, o artigo é a participação de Weil no dossiê "Heidegger" na

em seu nome, mas no lugar particular que Heidegger atribui a esses textos no conjunto da sua obra. Em comparação com outros manuscritos seus - como cursos, seminários e conferências - as 34 cadernetas que compõem os Cadernos têm um caráter muito distinto. Elas constituem Denktagebücher, quer dizer, diários que contêm reflexões de Heidegger e que permitem ao leitor entrar intimamente no diálogo que o filósofo estabelece com seu próprio pensar assim como com os acontecimentos de sua época. Além disso, o próprio Heidegger estabeleceu que - segundo relata seu filho e administrador da Gesamtausgabe, Hermann Heidegger - os Cadernos deviam aparecer depois da publicação dos outros volumes. Por causa da importância das referidas obras e devido à quantidade do legado de Heidegger (102 obras são previstas), estas começaram a ser publicadas antes do que foi estabelecido por seu autor".

3 Sobre a recepção dos Cadernos Negros de Heidegger, cf. LYRA, 2015. Como fica claro pelas citações, é justamente o texto de Lyra a base para essas nossas considerações

${ }^{4}$ É a opinião, por exemplo, de Barbara Cassin, Domenico Losurdo e Jonathan Rée. Os três registraram as próprias reações à leitura dos Scwarzen Hefte com os seguintes textos: Cassin escreveu para o Nouvel Observateur, de 20/09/2014, Nous savions tous que Heidegger avait été nazi; Losurdo, no The Guardian, em 10/03/2014, Heidegger's black notebooks aren't that surprising, e por fim, em 12/03/2014, Rée publica na Prospect Magazine, um título muito direto, In defence of Heidegger.

A recepção da filósofa brasileira Barbara Freitai Rouanet (2016, p. 964) segue uma direção um pouco mais acentuada: "Os textos [dos Cadernos negros] já editados e impressos que chegaram ao nosso conhecimento (a público) confirmam todas as suspeitas sobre o colaboracionismo de Heidegger com os nazistas e todos os seus preconceitos raciais contra os judeus, aos quais passa a atribuir sem grandes rodeios a culpa de sua própria extinção nas câmeras de gás em Auschwitz. Nos tais cadernos, Heidegger reafirma sua concepção do 'Führerstaat', glorifica o povo alemão, como eleito para salvar a Europa ('Abendland') esmagada entre o capitalismo anglo-saxônico e o comunismo soviético, declara o seu 'Denken' como herdeiro da verdadeira filosofia, que teve suas origens nos pré-socráticos, idealiza o poeta Hölderlin, como o novo Messias, que, de certa forma, antecipou a vinda do Messias Salvador (Hitler). Enfim, Heidegger dá razão aos seus críticos e fornece os comprovantes explícitos de tudo que eles já haviam destacado à luz de sua obra anterior (impressa), entre os quais Theodor W. Adorno, Jürgen Habermas, Herbert Marcuse, Hugo Ott, Victor Farias, Emmanuel Faye. O que antes era suspeita, agora é certeza! O próprio Heidegger fornece, sob forma de manuscritos (secretos), as 'provas' autênticas de seu envolvimento com o nazismo, usando a filosofia para mascarar suas ambições de poder.

${ }^{5}$ Naturalmente outros textos sobre os Scwarzen Hefte foram se somando ao de Trawny: na Itália, os livros de Donatella di Cesare (2014 e 2016) e de Friedrich-Wilhelm von Herrmann e Francesco Alfieri (2016) - que criticam fortemente o trabalho de Trawny -; na França, encontramos os textos de Jean-Luc Nancy (2015) e de Nicolas Weill (2018).

${ }^{6}$ Embora autores como von Herrmann e Alfieri afirmem que não há nada nos Cadernos negros que possa indicar adesão de Heidegger ao nazismo.

7 Provavelmente escrito em atenção a um pedido pessoal de Merleau-Ponty, como fica sugerido numa carta de Weil a Bataille, em 2 de abril de 1947 (cf. BATAILLE; WEIL, 2014, p. 133).

${ }^{8}$ O texto na língua original foi republicado ainda na revista Lignes, em 1987, depois no segundo volume da coletânea de textos de Weil (2003b), Philosophie et réalité. Uma tradução italiana foi preparada por Giuseppe Ciafrè como "Il caso Heidegger" e apareceu na revista Belfagor, em 1994. 
revista Les temps modernes. Ao redigi-lo, Weil se insere em um debate muito vivo na França, "lugar intelectual onde a polêmica [sobre Heidegger] é particularmente intensa" (LYRA, 2015, p. 59), embora, devemos reconhecer, sem encontrar o devido eco na continuidade das discussões. Com efeito, mantendo-nos sempre no terreno francês, surpreende o fato de que, por exemplo, Domenique Janicaud (1990) ignore inteiramente o nome de Eric Weil, e que Richard Wolin (1992) só Ihe faça uma única menção. ${ }^{9}$ Mesmo entre os estudiosos da obra weiliana, Le cas Heidegger encontra pouca atenção, tendo sido trabalhado de forma mais detida apenas por Gilbert Kirscher (1999), Francis Guibal (2001) e recentemente por Jean-François Rey (2014). ${ }^{10}$

A revista Les Temps Modernes abriu o dossiê sobe Heidegger com os artigos de Karl Löwith, Les implications politiques de la philosophie de l'existence chez Heidegger, e de Frédéric de Towarnicki, Visite à Martin Heidegger; enquanto o primeiro apresentava as "peças da acusação", o segundo publicava uma defesa. ${ }^{11}$ Por sua vez, Weil recusa, ao mesmo tempo, a defesa de Towarnicki e os argumentos de Löwith, que sugerem uma relação essencial entre a filosofia heideggeriana e o pensamento nazista. ${ }^{12}$ Le cas Heidegger segue outro caminho, pois, para o seu autor, a questão exige necessariamente que se distinga o que concerne ao cidadão Heidegger e o que toca a essência da sua filosofia. Para usar a boa síntese de Jean-François Rey (2014), trata-se de "escutar o filósofo e julgar o cidadão", num esforço que visa justamente avaliar a responsabilidade do indivíduo e do filósofo na relação com a história e com o mundo.

A distinção do que cabe ao cidadão daquilo que tange a sua filosofia estrutura o texto em duas partes fundamentais. Na primeira, toma-se a adesão explícita de Heidegger ao regime nazista, o que, segundo Guibal (2001, p. 192), "atesta uma cegueira política rara num intelectual desse nível".13 O fato é que "Heidegger se engajou no plano político, ele apresentou a sua escolha como expressão de uma decisão, por assim dizer, absoluta, e uma vez feita essa escolha, ela leva às suas consequências efetivas no plano da ação, ou seja, da política e da história." (KIRSCHER, 1999, p. 227). E por fim, mesmo depois da ruína do regime, Heidegger não questionou a sua política autoritária e expansionista, nem mesmo seu esforço de extermínio sistemático dos "sub-humanos". Na segunda, Weil considera a filosofia heideggeriana e reconhece que ela, por seu próprio princípio, exclui todo pensamento sobre a responsabilidade política, e, portanto, é incapaz de compreender a ação e de justificar o engajamento nazista ou qualquer outro tipo de compromisso. Logo, não se pode dizer que a filosofia de Heidegger seja nazista, e ele mesmo, ao colocar a linguagem de Ser e tempo à disposição de Hitler - no discurso do reitorado, por exemplo - "falsificou sua filosofia, porque abusou dela para lhe extorquir uma resposta política que ela não pode dar, visto que ela não pode sequer colocar a questão".

A afirmação weiliana de que entre a filosofia de Heidegger e o seu compromisso com Hitler não existe uma relação necessária, mas arbitrária, não defende o indivíduo nem a sua filosofia, mas enuncia um juízo propriamente filosófico sobre a insuficiência filosófica do existencialismo heideggeriano que ignora radicalmente a política e a história em sua integralidade

\footnotetext{
${ }_{9}^{9}$ Cf. WOLIN, 1992, p. 26, n. 24.

${ }^{10}$ Há de se dizer também que Jean Quillien nos artigos Heidegger et Weil, le destructeur et le bâtisseur, de 1982, e Philosophie et politique Heidegger, nazisme et la pensée française, de 1990, deu a Le cas Heidegger um espaço importante, mesmo sem fazer dele objeto principal de estudo.

${ }^{11}$ Vale recordar que no mesmo fascículo do texto weiliano, encontra-se o artigo do fenomenólogo de Lovaina, Alphonse de WaeIhens, La philosophie de Martin Heidegger et le nazisme, no qual o autor sustenta a tese de que a filosofia não traz responsabilidades políticas e que a atitude pessoal do filósofo em um certo momento é completamente indiferente, defendendo o contrário de Weil que denuncia a presumida apoliticidade do pensamento de Heidegger e as suas responsabilidades.

${ }^{12}$ Grosso modo, a resposta de Weil a Löwith aponta para a falta de transcendência em Heidegger, logo, a sua filosofia não pode levar ao nazismo, o que aponta ainda para um paradoxo: Heidegger interpretou bem uma realidade má.

${ }^{13}$ Claudia Koonz (2005, p. 65s) em seu The Nazi Conscience, dedica um capítulo aos "aliados na Academia", ou seja, aos intelectuais que, como Heidegger, aderiram ao nazismo. A autora trata sobretudo da "súbita conversão ao nazismo de três distintos acadêmicos": além de Heidegger, o teórico da política Carl Schmitt e o teólogo Gerhard Kittel.
} 
como dimensões da realidade e do homem. ${ }^{14} \mathrm{O}$ fato é que, para Weil, a filosofia de Heidegger não consegue perceber a realidade como totalidade concreta nem permite ao indivíduo encontrar nela um lugar e um sentido ${ }^{15}$, e para pensar esta totalidade concreta e o indivíduo nela inserido, é preciso pensar do ponto de vista da razão que vê estes momentos diferentes e procura articulá-los.

É justamente essa articulação concreta que um pensamento sempre posto do ponto de vista do indivíduo não consegue apreender. É ainda nesse ponto que Weil prende o pensamento de Heidegger à filosofia transcendental, como busca das condições de possibilidade da experiência, e denuncia a ambuiguidade desse tipo de empreendimento, pois "nele a realidade deve ser compreendida a partir da condição de possibilidade, mas esta repousa sobre a realidade da qual se parte sem fundá-la previamente." (KIRSCHER, 1999, p. 229).

Para Weil, esse tipo de filosofia "não conhece a política", em outras palavras, não dispõe de meio algum para distinguir o bem do mal, a razão da violência, enquanto a filosofia deve necessariamente descobrir e compreender a violência como problema da política, como possibilidade a ser superada.

Por fim, diferentemente de Faye, por exemplo, "Weil sabe reconhecer toda a força filosófica e toda a importância histórico-cultural do pensamento heideggeriano." (GUIBAL, 2001, p. 197). Com efeito, afirma sem reservas que Heidegger soube perceber, traduzir e expressar, "com o vigor que a filosofia só possui em momentos cruciais da história", as tensões e as contradições de uma época que "entronizou a finitude" (WEIL, 2003a, p. 100). Heidegger representa, então, um gênero de filosofia cujo conhecimento é imprescindível justamente porque revela uma parte da realidade alemã, não porque justifique o nacional-socialismo; dito de outra forma, uma filosofia que exprime a realidade na qual o nazismo se tornou possível - não necessário. Do mesmo modo, permite perceber a aporia constitutiva de uma filosofia que faz do indivíduo o seu fundamento e o seu ponto de partida, enquanto, para Weil, o indivíduo é sempre o problema da filosofia.

A leitura de Le cas Heidegger é então uma oportunidade para pensar a responsabilidade social e política do filósofo, de reafirmar fortemente o fato de que o intelectual também, como qualquer outro cidadão, é obrigado a prestar contas daquilo que faz ou deixa de fazer no terreno da ação, quer dizer, da política e da história.

\section{Referências}

CASSIN, B. Nous savions tous que heidegger avait été nazi. Dispinível em: https://bibliobs. nouvelobs.com/essais/20140919.OBS9704/barbara-cassin-nous-savions-tous-que-heideggeravait-ete-nazi.html.

DI CESARE, D. Heidegger e gli ebrei. I Quaderni neri. Torino: Bollati Boringhieri, 2014.

DI CESARE, D. I Quaderni neri di Heidegger. Milano, Mimesis, 2016.

FARÍAS, V. Heidegger y el nazismo. Fondo de Cultura Económica, Santiago, 1998.

FAYE, E. Heidegger, l'introduction du nazisme dans la philosophie. Paris: Albin Michel, 2005.

\footnotetext{
${ }^{14}$ Essa é a tese fundamental de Eric Weil, aqui desenvolvida rapidamente, mas detalhada em textos como Raison, morale et politique (WEIL, 1991b, p. 326-340), Masses et individus historiques (WEIL, 1991b, p. 255-325), Responsabilité politique (WEIL, 1991b, p. 341350) e La morale de l'individu et le politique (WEIL, 1991a, p. 159-174).

15 “Para Weil, esta totalidade concreta deve ser pensada antes de tudo como comunidade política articulada segundo os diferentes momentos já concebidos por Hegel, não apenas momento da pessoa jurídica e da individualidade abstrata, mas ainda momento da individualidade concreta, momento do homem na sociedade da necessidade e do trabalho, momento do cidadão na dimensão política propriamente dita e na história das comunidades políticas se relacionando umas com as outras" (KIRSCHER, 1999, p. 228).
} 
GUIBAL, F. Philosophie, modernité, politique. Eric Weil, critique de Martin Heidegger. Revue des Sciences Religieuses, v. 75, n. 2, p. 190-219, 2001.s

JANICAUD, D. L'ombre de cette pensée. Heidegger et la question politique. Paris: Jérôme Millon, 1990. KIRSCHER, G. Eric Weil ou la raison de la philosophie. Villeneuve d'Ascq, Press Universitaires du Septentrion, 1999.

KOONZ, C. La consciência nazi. La formación del fundamentalismo étnico del Tercer Reich. Barcelona: Paidos, 2005.

LOSURDO, D. Heidegger's black notebooks aren't that surprising. In: https://www.theguardian.com/ commentisfree/2014/mar/19/heidegger-german-philosopher-black-books-not-surprising-nazi.

LÖWITH, K. Les implications politiques de la philosophie de l'existence chez Heidegger. Les Temps Modernes, v. 14, p. 343-360, 1946.

LYRA, E. Sobre a recepção dos Cadernos Negros de Heidegger. O que nos faz pensar, v. 36, 2015, p. 53-74./

NANCY, J.-L. Banalité de Heidegger. Paris: Galilée, 2015.

QUILLIEN, J. Philosophie et politique Heidegger, nazisme et la pensée française. Germanica, v. 8 1990, p. 103-142.

QUILLIEN, J. Heidegger et Weil, le destructeur et le bâtisseur. Cahiers philosophique, v. 10, 1982, p. 7-62.

RÉE, J. In defense of Heidegger. In: http://www.prospectmagazine.co.uk/arts-and-books/ in-defence-of-heidegger.

REY, J.-F. Écouter le philosophe, juger le citoyen ? Eric Weil et le cas Heidegger. In LESCOURRET, M.-A. (Ed.). La dette et la distance. De quelques élèves et lecteurs juifs de Heidegger. Paris: Editions de l'Éclat, 2014, p. 223-232.

ROUANET, B. Habermas e Heideiier: uma discórdia filosófica - reflexões sobre os Cadernos negros de Heidegger. Sociedade e Estado, v. 31, p. 955-968, 2016.

STEPHAN, D. Martín Heidegger y los Cuardenos Negros: más que la mera reactivación de un viejo debate. Alpha, v. 42, p. 235-251, 2016.

TOWARNICKI, F. Visite à Martin Heidegger. Les Temps Modernes, v. 4, p. 717-724, 1946.

VON HERRMANN, F. ALFIERI, F. Martin Heidegger. La verità sui Quaderni neri. Brescia: Morcelliana, 2016.

WAELHENS, A. La philosophie de Martin Heidegger et le nazisme. Les Temps Modernes, v. 22, p. 115-127, 1947.

WEIL, E. Le cas Heidegger. Les Temps Modernes, v. 2, n. 22, p. 128-138, 1947; Lignes, v. 2, p. 139-151, 1987.

WEIL, E. Il caso Heidegger. Trad. G. Ciafrè. Belfagor, v. 49, n.1, p. 55-64, 1994.

WEIL, E. Essais et conférences 1. Paris: Vrin, 1991a.

WEIL, E. Essais et conférences 2. Paris: Vrin, 1991b.

WEIL, E. Philosophie et réalité 1. Paris: Beauchesne, 2003a.

WEIL, E. Philosophie et réalité 2. Paris: Beauchesne, 2003b, p. 254-266.

WEILL, N. Heidegger et les Cahiers noirs. Mystique du ressentiment. Paris: CNRS, 2018.

WOLIN, R. La politique de l'être. La pensée politique de Martin Heidegger. Paris: Kimé, 1992. 


\section{O caso Heidegger}

WEIL, E. Le cas Heidegger. Les Temps Modernes 2/22 (1947), p. 128-138

O dossiê Heidegger continua a aumentar. No entanto, temos a impressão de que faltem nele peças essenciais, documentos que possam trazer novos argumentos, num ou noutro sentido. Evidentemente, não está excluída a possibilidade de que se encontre outro apelo inflamado em favor do Führer, que apareça alguma outra carta enviada pela Sra. Heidegger (ou por um filho, por outro parente, ou mesmo pelo próprio Heidegger) a um "não-ariano" ou a um colega suspeito de tibieza em relação a Hitler: mas isso dificilmente mudaria algo no processo. Löwith ${ }^{16}$ apresentou as peças da acusação (uma parte das peças), Towarnick ${ }^{17}$ publicou uma defesa de Heidegger (mais de Heidegger do que para Heidegger: seria fácil provar, usando documentos assinados pelo autor, que Towarnicki é muito mais o tradutor do que advogado de seu cliente): é hora de deliberar.

Resumamos os fatos: Heidegger, célebre professor na Universidade de Friburgo, foi feito reitor na primavera de 1933, e se inscreveu "em prol dos interesses da universidade", no partido nacional-socialista. Até então, ele jamais havia feito política. Admitamos isso, embora haja testemunhos de que Heidegger, no mais tardar, desde 1932, já fosse considerado "nazista" por boa parte de seus ouvintes. Ele permaneceu como reitor até fevereiro de 1934, quando renunciou ao cargo porque dois de seus colegas foram ameaçados de demissão e porque ele mesmo decidiu fazê-lo antes que esta ameaça aparecesse, continuou a ministrar seus cursos que, mesmo não sendo bem vistos por alguns membros do partido nazista, não tinham um caráter suficientemente perigoso para que se hesitasse em lhe oferecer a reitoria de Berlim - "foi obrigado a interromper seus cursos em 1937-1938", mas pôde retomá-los e continuar com eles em plena guerra, publicou sem interrupção, embora com dificuldades, particularmente no plano publicitário, viu-se privado do direito de participar de congressos internacionais (não se sabe se lhe foi recusado o visto de saída ou simplesmente a qualidade de representante oficial da filosofia alemã), por sua vez, se recusou a fazer viagens de propaganda no exterior, não porque desaprovasse a política do Reich, mas porque, como ele mesmo afirma de forma engenhosa, "foi proibido de expressar abertamente seu pensamento em seu próprio país" - e agora pede, com a ajuda dessas provas de inocência, que o absolvamos.

Towarnicki se esquece de mencionar algumas obras de circunstância, que Löwith faz muito bem em citar: o discurso de ingresso na função de novo reitor, com o seu apelo à fidelidade ao Führer, o discurso em memória de [Albert Leo] Schlageter, o apelo à universidade e ao povo alemão no momento das eleições, após a saída da Alemanha da Liga das Nações: mesmo os olhos mais treinados e mais complacentes não encontrarão ali nada que contradiga a ação de Hitler (assim como os olhos mais maliciosos, aqueles da censura nazista, não encontraram nada parecido). É a linguagem nazista, a moral nazista, o pensamento (sit venia verbo) nazista, o sentimento nazista. Não é a filosofia nazista, e é sobre isso que Heidegger acredita que se deva decidir. Mas é preciso entender: se Heidegger não é um nazista ortodoxo, se foi criticado (entre parênteses: ficamos surpresos ao encontrar os dois qualificativos de "odiosos" $\mathrm{e}$ "incompreensíveis" - Towarnicki, p. 720; esses ataques eram odiosos porque seus adversários não compreendiam Heidegger, mas tais ataques teriam mesmo cessado se ele tivesse sido compreendido?), se [Alfred] Baeumler o olhava com desconfiança, é porque Heidegger não era um materialista biologista, só porque, para ele, o logos tinha precedência sobre a natureza tal como ela é com-

\footnotetext{
${ }^{16}$ LÖWITH, K. Les implications politiques de la philosophie de l'existence chez Heidegger. Les Temps Modernes 14 (1946), p. 343-360.

17 TOWARNICKI, F. Visite à Martin Heidegger. Les Temps Modernes 4 (1946), p. 717-724.
} 
preendida pela ciência. Pois bem, Heidegger evitou um absurdo filosófico, até mesmo protestou contra esse absurdo. Porém, ele não foi acusado de biologismo, de "beaumlerismo" ou de "rosenbergianismo", mas de hitlerismo. Ele está sendo julgado no plano político e sua defesa nesse plano não é apenas fraca, ela é inexistente. São muitos os ladrões que poderiam jurar em sua alma e consciência que nunca violentaram uma jovem: mas normalmente eles não se servem desse argumento diante dos tribunais.

Heidegger aprovou a ascensão de Hitler ao poder, não ficou muito constrangido com toda a história do primeiro ano do Reich milenar, aprovou publicamente o rompimento com a Liga das Nações, jogou todo o seu peso moral sobre seus alunos e sobre a opinião pública de seu país para que Hitler fosse o futuro da Alemanha, e ficou desapontado ao ver que o Reich poderia dispensar seus serviços, uma vez que não precisava de filósofo algum. Portanto, ele só poderia lamentar o fato de o nazismo ter-lhe sido ingrato. Eis uma causa que Heidegger talvez ganhasse perante um tribunal objetivo; em todo caso, poderia demonstrar que fez despesas.

A vontade do povo alemão de ser responsável apenas diante de si mesmo, ele declarava em seu apelo de 10 de novembro de 1933, é "a partida de uma jovem purificada que crê de novo (zurückwächst) em suas próprias raízes... O povo recupera a verdade de sua vontade de existir (Daseinwille): porque (devemos ter cuidado: Heidegger indica agora as bases, segundo ele, filosoficamente sólidas, que ele pode colocar à disposição do partido) verdade é o ser-aberto (ou visível: Offenbarkeit) do que torna seguro, claro e forte um povo em sua ação e em seu saber. E essa vontade de saber delimita a exigência do saber. E a partir daí, enfim, são medidos os limites dentro dos quais a questão e a pesquisa autênticas devem se fundamentar e se legitimar (ou fornecer suas provas). Desta origem provém para nós a ciência. Ela está ligada à necessidade da existência nacional (völkisch) responsável diante de si mesma... Saber (wissend-sein) significa para nós: ter poder sobre as coisas com clareza e estar decidido a agir. Nós nos separamos da idolatria de um pensar sem solo (ou fundo) ou poder. Assistimos o fim de uma filosofia que o serve". Heidegger tem razão: se Hitler tivesse compreendido algo da filosofia, essa "verdade" teria Ihe prestado um serviço melhor do que seu biologismo, uma vez que também teria sido capaz de justificar absolutamente tudo, e que, como vantagem suplementar e não negligenciável, teria sido menos constrangedora para a propaganda externa, portanto mais nobre do que a doutrina do povo superior pela graça de Darwin.

Heidegger não se interessa pelo processo que ele poderia sustentar contra Hitler, e ele está certo: a casa está falida, o chefe, morto. Mas é surpreendente que agora ele aspire ao papel de servo ruim, inclusive de um servo dos inimigos do chefe, porque este não deu o devido valor aos meios que ele colocou à disposição da empresa. Houve uma desavença, isso já está entendido; mas não foi Heidegger que a procurou. Ele não obteve o que pedia ao menos implicitamente, o lugar de Führer do Espírito alemão; mas é um assunto entre Hitler e ele. Nós podemos concluir.

Podemos concluir, mas não podemos passar adiante sem tentar aprender a lição. O que é assustador nesse caso não é tanto o que Heidegger fez no início e não fez depois, é a sua defesa. Um professor de filosofia desce à arena: isso é bom; ele se engana: isso é humano, sobretudo quando se é professor; ele declara ter estado do lado certo: é nisso que Heidegger se torna um caso representativo, não dizemos dos alemães, mas certamente de boa parte dos alemães.

O ex-embaixador alemão, [Christian August Ulrich] von Hassell, foi um dos líderes da "resistência" alemã, depois de ter servido a Hitler até 1938. Ele morreu heroicamente depois de 20 de julho de 1944. Nos diários desse autêntico nazista, recentemente publicados, existe um projeto de paz, apresentado pela resistência alemã aos ingleses, que prevê a substituição do regime nacional-socialista por um Estado cristão; tudo o que se pede em troca é o reconheci- 
mento da anexação da Áustria e da região dos Sudetos, com o restabelecimento da fronteira de 1914 ao leste - em suma, mantinha-se tudo o que Hitler tomou; este último oferecido em holocausto, já que não se podia mais usá-lo para nada. Heidegger pensa do mesmo jeito: a luta pela Grande Alemanha, perfeita; a ditadura, nem uma palavra de reprovação; o rompimento com a Liga das Nações, aplausos frenéticos. Mas Heidegger era contra o materialismo biológico, como von Hassell era contrário ao paganismo.

Há uma diferença, mas não é uma vantagem para Heidegger: von Hassell lutou contra Hitler, Heidegger criticou a filosofia de Rosenberg. Certamente, ninguém está pedindo a Heidegger que arrisque sua vida em uma empreitada desesperadamente perigosa; mas ele devia compreender que não pode se fechar na posição do homem de ciência ou se cobrir com a inocência do Filósofo desprendido dos assuntos deste mundo. Heidegger teria uma excelente defesa se quisesse dizer que ele, filósofo da decisão, se decidiu, com plena responsabilidade, pelo que tomou como destino, que ele compreendeu, depois, que esse destino era apenas a farsa sangrenta da não-responsabilidade, da recusa da responsabilidade, a traição de toda autenticidade, o subterfúgio raso e desprezível de uma vontade de poder primitiva e, por essa razão, negadora de todo "ser si-mesmo", era o risco era um "ir de encontro à morte", mas da morte dos outros - em uma palavra, que ele compreendeu. Mas Heidegger não compreendeu que agiu e que é responsável por isso no plano da ação, no qual, nesse mundo, os homens são pesados e julgados. E porque não quer compreender a parte que teve numa guerra supérflua e por isso duplamente atroz, tudo o que ele alega é apenas subterfúgio e ilusão. Ele quis o que Hitler quis (ou então o pensador da responsabilidade e do engajamento teria se decidido sem ter lido Mein Kampf? Isso agravaria o seu caso); hoje ele pede que esqueçamos, não que perdoemos, o que seria possível, mas que esqueçamos, como se a Terra inteira não fedesse a cadáver, graças ao homem em nome de quem ele jurou e fez seus alunos jurarem. Então, ele estaria pronto para fazer tudo de novo amanhã, com a única condição de substituir o biologismo por sua "verdade" ad usum tyranni?

Eis o caso do cidadão Heidegger. Mas essa é apenas uma de suas facetas e, no que diz respeito à pessoa de Heidegger, a menos importante. Poderíamos estudar o fenômeno alemão a partir de outros exemplos, como se faz atualmente como a literatura alemã depois de 1918: apelamos ao espírito da história, quando acreditamos ter alcançado a vitória; mas, quando faIhamos, falamos de circunstâncias, de acidentes, de encadeamentos, de boa e de má vontade. A História (com H maiúsculo) é sem apelo, enquanto quisermos recusar seu tribunal. Ainda uma vez, Heidegger não está sozinho.

Ele está sozinho quando se trata de filosofia. Pois Heidegger é o único filósofo importante que se pronunciou em favor de Hitler, e a questão mais candente é saber se a sua decisão política envolve a sua filosofia e, por sua filosofia, a própria filosofia enquanto tal. Löwith sustentou que a política e a filosofia de Heidegger não se separam, que seu niilismo devia levá-lo ao nazismo e que toda filosofia do tipo daquela que ele representa, toda filosofia sem eternidade, leva a isso. Essa filosofia enunciou a essência da época, seu princípio "corresponde... ao estado radical da situação real", e "a verdade da atual existência alemã se encontra sempre, e mais do que nunca, em Heidegger... se (grifa Löwith) a verdade do Dasein for realmente temporal e histórica", em outras palavras, se não houver Eternidade.

Löwith é um pouco como Balaão, o profeta dos moabitas que havia partido para amaldiçoar Israel e cujos lábios proferiam apenas bênçãos. É bem verdade que, se existe uma Eternidade e se essa Eternidade for acessível ao homem, o pensamento do nacionalismo absoluto - é a isso que se reduz a "verdade" heideggeriana na política - é ilegítimo e falso: a fé transcendente, toda fé transcendente, exclui o relativismo ético e proíbe o homem, se não de morrer, 
ao menos de matar pelas coisas deste mundo. Mas hesitamos em dar o "salto brusco" que, para Löwith, leva para além do desespero (Löwith fala de outras possibilidades além da fé em um criador, sem indicar a que está fazendo alusão), e preferimos procurar primeiro dentro disso, não concederemos à filosofia heideggeriana o que Löwith the concede. Heidegger teria interpretado uma realidade ruim: daí seguiria que aqueles que, sem dar o salto, não concordavam com sua filosofia da historicidade e suas consequências políticas, teriam razão por razões filosoficamente falsas. Condenar a atitude de Heidegger seria então como se quiséssemos ver no termômetro a causa da febre, porque os dois subiam ao mesmo tempo: nem Heidegger nem Hitler seriam culpados daquilo que um cometeu e que o outro aprovou, e Löwith seria feito juiz apenas para absolver os inculpados à custa da "fatalidade" - ou da filosofia sem a Eternidade. Tem-se que chegar a isso? Deve-se mesmo dizer que a culpa de Heidegger foi ser um bom filósofo, na medida em que uma filosofia baseada no tempo e na história pode ser boa e que, com essa filosofia, ele só poderia ser nazista?

Nós não acreditamos nisso. É evidente que a possibilidade de uma filosofia não eterna não pode ser discutida por alto e por ocasião de um incidente histórico; é igualmente evidente que não se pode afirmar que ela seja impossível, simplesmente porque Heidegger entrou no partido nazista. No entanto, o que temos o direito de declarar é que o vínculo entre existencialismo e nazismo era ilegítimo em Heidegger, de acordo com os próprios princípios de sua filosofia, e que estaríamos cometendo um erro ao estabelecer uma relação de causa e efeito, onde existe apenas arbítrio - e onde não pode haver outra coisa. A "verdade" alemã não pode ser deduzida de Ser e Tempo.

O existencialismo de Heidegger (descartamos a questão de saber até que ponto isso se aplica a todo existencialismo sem transcendência concreta) é uma filosofia da reflexão que, como qualquer filosofia da reflexão, tende do indivíduo para o Ser. Ela se torna então necessariamente filosofia transcendental, busca das condições de possibilidade da experiência: esforço essencialmente ambíguo, pois, por um lado, não pode definir o que, para ele, é uma condição, a menos que se contente com a simples não-contradição, e que, por outro lado, deve basear a realidade (legítima) na possibilidade dessa realidade, realidade cuja possibilidade só pode ser descoberta na realidade que teve que ser legitimada e que, no entanto, deve ser tomada como é, para permitir a partida. Então somos obrigados a passar da realidade à ideia de toda realidade possível (Ser), para estarmos seguros de que não fomos enganados por uma escolha do essencial que seria inevitavelmente uma escolha arbitrária. Ora, o homem, tomado como indivíduo, não está à altura do totum das possibilidades; se ele pode pensá-la formalmente, não pode realizá-la, e é livre, porque não é suficiente; se o fosse, ele não precisaria mais escolher em sua vida, e a palavra liberdade perderia seu sentido. Ele pode falar do Ser, mas só pode fazê-lo formalmente, quer dizer, só pode descobrir as formas vazias nas quais toda realidade deve entrar para que seja realidade para ele; o que entra aí, ele não pode prever nem decidir.

Não parece que uma filosofia que comece no indivíduo possa levar a outros resultados, pelo menos isso não foi feito até agora. Se um outro começo é possível ou necessário, nós nos resguardaremos de levantar esse problema: Platão, que reserva o indivíduo aos seus mitos, Aristóteles, Hegel se opondo a Kant (e ao kantiano Heidegger), como a toda tradição cristã sobre esse tema - e seria um tanto presunçoso querer se manter acima dessa mistura ou se pronunciar do alto. Mas nada nos obriga a tomar partido, quando se trata simplesmente de falar do nazismo de Heidegger. Sua filosofia é uma filosofia da reflexão, e isso basta para mostrar que ele está enganado, ou que quer enganar, se der razões filosóficas à sua escolha política.

\footnotetext{
* Referimo-nos apenas à obra heideggeriana anterior a 1933.
} 
Filosoficamente, o filósofo transcendental não pode basear sua decisão política, ele pode, no máximo, constatar que certas escolhas lhe são proibidas, se quiser permanecer consequente consigo mesmo: por exemplo, ele não pode aprovar uma teoria política que faça do homem, fonte da verdade, uma coisa no mundo. No entanto, dessa forma, ele não dispõe de uma regra positiva de conduta - por uma razão muito simples, a saber, que na política o sujeito nunca é o indivíduo, mas uma comunidade histórica ou futura, e que na filosofia transcendental, não há nenhum meio que permita decidir qual é a comunidade - povo, Estado, raça, humanidade, civilização, para citar apenas algumas possibilidades - que, no plano histórico, é $a$ comunidade decisiva. A filosofia da reflexão, ao se voltar para comunidades reais, pode abstrai-las, como condição de possibilidade da história, a forma "comunidade"; não pode preenchê-la, assim como não se pode falar de tempo e de história, mas somente de temporalidade e de historicidade. Heidegger, ao identificar a verdade histórica concreta com a vontade do povo alemão, fez uma escolha que era admissível em sua filosofia (o nazismo se torna nacionalismo radical), como era admissível toda escolha entre as possibilidades políticas: com a alma filosófica em paz, ele poderia ter se tornado anarquista, liberal, conservador, comunista (não marxista, dado que para Marx, como para Hegel, não se trata de historicidade, mas da história una e total que o indivíduo pode apenas aceitar ou recusar, mas que não pode mais querer "criar", uma vez que, no pensamento, ele passou ao plano do universal).

A culpa do existencialismo heideggeriano se mostra, portanto, se pedirmos à filosofia que leve o homem a conclusões histórica e politicamente concretas, não a alguma decisão, porque ela leva apenas à decisão. Colocá-la a serviço do nacionalismo radical é um ato inteiramente arbitrário e gratuito, e embora não seja defendido, lícito ou prescrito, é compreensível, pois esta filosofia separa radicalmente o filósofo da possibilidade do homem que deve viver numa dada realidade, realidade que, no entanto, o filósofo, enquanto filósofo, deve compreender apenas em sua forma. Há filosofias que engajam o filósofo: a de Heidegger não é uma delas. Ela não é reacionária nem revolucionária, ela não conhece a política.

E porque Heidegger falsificou a sua filosofia, porque abusou dela para the extorquir uma resposta política que ela não pode dar, visto que ela não pode sequer colocar a questão - justamente por isso, podemos dizer que essa filosofia, em sua forma pura, é parcialmente verdadeira, verdadeira no sentido que Hegel dá a essa palavra: ela revela uma parte da realidade alemã. Ela não justifica o nacional-socialismo, mas exprime essa realidade alemã na qual ele foi possível, sem ser por isso necessário. Dito de outro modo, mostra a realidade do indivíduo isolado que não tem mais e que não tem ainda tradição. Pois o indivíduo isolado e que se compreende como tal deve ao mesmo tempo negar tudo o que o transcende concretamente, sem poder renunciar à transcendência que se torna uma categoria formal da existência, um existencial: ele se encontra sempre diante de algo, desde que ele fale e pense e não tenha entrado no êxtase místico, e esse algo, esse transcendente, só pode aparecer sob as espécies do Nada, do que lhe acontece e que o nega, em uma palavra: da violência. A contraparte está na afirmação da liberdade formal, da decisão formal, da aceitação formal de um destino formal. E é um fato que o espírito alemão estava inebriado de "decisionismo" muito antes de Heidegger. Mas disso não decorre que o "tragicismo" tivesse que levar ao nazismo: a violência é um momento da política (e da realidade), ela não é necessariamente a totalidade, e os homens (não o indivíduo) podem querer subjugá-la. Mas esta decisão concreta supõe um futuro concreto, que Heidegger, filósofo do presente alemão do período entre as duas guerras (entre aquela de 1870 e a última) não quer encarar, porque, então, ele deveria abandonar essa existência que "é sempre a minha": o bem e o mal não se distinguem na política; a distinção sequer tem sentido para o filósofo transcendental da existência; como o seu país, ele pode se 
tornar nazista, sem ser empurrado pra isso por sua filosofia, assim como o seu povo não foi empurrado para o nazismo por sua realidade.

Uma filosofia que parte do indivíduo concreto e que compreende o termo "concreto" ingenuamente como um irredutível (dissemos por que ela não pode fazer de outro modo), resulta na decisão vazia, decisão pela decisão, não importa qual, ou na fé transcendental (em relação à filosofia): como ela escaparia disso, uma vez que proíbe tanto a theôria grega, quanto a ação razoável moderna? Mas seria errado ver neste resultado uma refutação ao existencialismo heideggeriano; ele constitui a dialética verdadeira do indivíduo que quer se manter em seu ser, tal como ele o percebe imediatamente, e acaba por se encontrar jogado por não se sabe quem em não se sabe o quê - a menos que se renuncie a reflexão (inclusive sobre as categorias formais da existência) como um resíduo de eternidade e se volte à expressão imediata do sentimento, para a poesia. Se se quiser mais alguma coisa, é preciso falar dos homens neste mundo, não da existência e do seu caráter mundano, deve-se fazer do indivíduo o problema, não a base da filosofia. Caso contrário, tudo é permitido ao indivíduo e a todos os grupos (que são formados apenas pelo consentimento arbitrário de seus membros) porque nada é "sensato": liberdade para tudo, não importa o que.

Essas considerações podem ser feitas para apoiar a defesa de Heidegger; elas resgatam o existencialismo heideggeriano. Talvez a sua filosofia seja insuficiente: ela não poderia ser qualificada como falsa simplesmente porque Heidegger aderiu ao partido nazista, pois para provar que ela é insuficiente, é preciso demonstrar que uma filosofia da totalidade concreta - que seria suficiente - pode reservar ao indivíduo o lugar ao qual ele jamais renunciará. A importância do existencialismo heideggeriano reside no fato de ele ter feito novamente essa pergunta com o vigor que a filosofia só possui em momentos cruciais da história. Esse mérito continua, e é imenso. Que seu autor seja um indivíduo de convicções políticas que insistimos em qualificar como inadmissíveis, que tenha assumido até agora uma atitude que, dependendo do ponto de vista, podemos caracterizar como revoltante ou simplesmente como grotesca, isso não exime ninguém de levar a sério a sua filosofia - mesmo que seja para refutá-la; seus problemas são problemas para toda filosofia séria, embora não tenham necessariamente a função de fundamentos que possuem em Heidegger, ou, para dizer a mesma coisa de outra maneira, que não seja evidente que a filosofia deva partir do cogito interpretado como subjetividade individual. Sua filosofia é importante, porque obriga a repensar concretamente os problemas que, formalmente, são sempre os mesmos. O filósofo Heidegger, é preciso ouvi-lo, sobretudo quando não se está de acordo com ele.

Quanto ao homem e ao educador da juventude, talvez seja suficiente citar, como resumo, uma página do livro de Karl Jaspers A questão da culpa (ZURIQUE, 1946, p. 46 sq). ${ }^{18}$

"Muitos intelectuais que, em 1933, se envolveram, que desejavam para si postos de liderança, que, publicamente tomaram posição pelo novo poder e sua Weltanschauung - que, depois, colocados pessoalmente em segundo plano, ficaram descontentes - que mantiveram, entretanto, na maioria dos casos, uma atitude positiva, até que, a partir de 1942, o curso dos acontecimentos militares tornou previsível o resultado desfavorável e fez deles, só então, oponentes completos, esses intelectuais têm o sentimento de terem sofrido sob os nazistas e, por isso, de serem qualificados para o que viria. Eles próprios se tomam como antinazistas. Durante todos esses anos, existia uma ideologia desses nazistas intelectuais: [afirmavam que] procla-

\footnotetext{
${ }^{18}$ O trecho citado por Weil corresponde às páginas 63 e 64 da edição brasileira de A questão da culpa, tradução de Claudia Dornbusch (São Paulo: Todavia, 2018). Aqui seguimos a versão de Weil. [NdT].
} 
mavam a verdade nas coisas do espírito, sem preconceitos - eles preservavam a tradição do espírito alemão - eles impediam destruições - eles alcançavam resultados úteis em cada detalhe.

Entre eles, talvez encontremos alguns que sejam culpados por um tipo de rigidez em sua forma de pensar que, sem se identificar com as doutrinas do partido, se prende, porém, à postura interna do nacional-socialismo, sob a aparência de uma transformação e de uma hostilidade, sem se esclarecer. Com essa forma de pensar, talvez eles originalmente sejam aparentados com aquilo que no nacional-socialismo foi a essência desumana, ditatorial, niilista e contrária à existência. Quem, por ser pessoa madura em 1933, tinha a íntima convicção de que não tinha suas raízes apenas em um erro político, mas em um sentimento existencial (Daseinsgefühl) aumentado pelo nacional-socialismo, não se tornará puro, exceto por uma refundição, que talvez deva ir mais fundo que todas as outras. Sem essa refundição, quem se comportou dessa forma em 1933, ficaria sem solidez interior (brüching) e inclinado a outros fanatismos. Quem participou da loucura racista, quem compartilhou das ilusões de uma reconstrução fundada em mentiras, quem já naquela época se acomodava aos crimes perpetrados - não apenas é responsável politicamente, mas deve se renovar moralmente. Se é capaz de fazê-lo e como o fará é assunto exclusivo seu, e difícil de julgar de fora".

O que pode ser julgado de fora - qualquer que seja a questão moral - é a responsabilidade política que um homem incorreu, e é o sentido que ele mostra dessa responsabilidade quando se trata de aceitar as consequências de seus atos e de repará-los na medida do possível. Enquanto Heidegger continuar a não querer ver o primeiro ponto e, por consequência, se recusar a considerar o segundo...

\footnotetext{
Sobre o tradutor

Judikael Castelo Branco

Professor da Universidade Federal do Tocantins (UFT) no curso de Licenciatura em Filosofia e no Programa de Mestrado Profissional em Filosofia. Doutor em Filosofia pela Universidade Federal do Ceará (UFC) e pela Université Charles de Gaulle (Lille 3). Atualmente desenvolve pesquisas nas áreas de Ética e Filosofia política, com especial interesse pelo pensamento de Eric Weil, Hannah Arendt e Charles Taylor. Membro do GT Eric Weil da ANPOF.
}

Recebido: $7 / 2 / 2020$

Aprovado: $20 / 3 / 2020$ 